RAD Conference Proceedings, vol. 3, pp. 123-126, 2018

ISSN 2466-4626 (online) | DOI: 10.21175/RadProc.2018.27

www.rad-proceedings.org

\title{
ANALYSIS AND CONSTRUCTION OF THE HIGH DENSITY STORAGE RACKS FOR SPENT FUEL OF THE RESEARCH REACTOR IEA-R1
}

\author{
Antonio Carlos Iglesias Rodrigues*, Tufic Madi Filho, Davilson Gomes da Silva
}

Instituto de Pesquisas Energéticas e Nucleares (IPEN / CNEN - SP), São Paulo, Brazil

\begin{abstract}
The IEA-R1 research reactor works $40 h$ weekly, with $4.5 \mathrm{Mw}$ power. The storage rack for spent fuel elements has less than half of its initial capacity. Under these conditions, the reactor operating for $32 h / w e e k$ will have 3 spent fuel by year, approximately 3 utilization rate Positions/year; thus, we will have only about six years of capacity for storage. Since the desired service life of the IEA-R1 is at least another 20 years, it will be necessary to increase the storage capacity of spent fuel by doubling the wet storage in the reactor's pool. 3M's neutron absorber Boralcan ${ }^{T M}$ was chosen after reviewing the literature about available materials for the construction of a new storage rack. This work presents studies for the construction of new storage racks with double of capacity using the same place of the current ones. Criticality safety analysis was performed with MCNP-5 Monte Carlo code, using two Evaluated Nuclear Data Files (ENDF/B-VI and ENDF/B-VII) in calculations, and subsequently, the results were compared. The full charge of the storage rack with only new fuel elements (maximum reactivity) was considered to calculate the keff. The results obtained in the simulations show that it is possible doubling the storage capacity of the spent fuel elements. Additionally, it complies with safety limits established by International Atomic Energy Agency (IAEA) and Brazilian Commission of Nuclear Energy (CNEN) standards to the criticality criteria (keff <0.95). This is only possible with the use of neutron absorber material.
\end{abstract}

Key words: Spent fuel storage, $M C N P-5$, Boron

\section{INTRODUCTION}

The IEA-R1 reactor is open pool type and reached its first criticality on September 16, 1957. During the first three years of operation, the reactor power was up to $1 \mathrm{MW}$. From 1960 to 1995 , the operating regime of the reactor was 40 hours per week at a power of $2 \mathrm{MW}$. From 1995, the Reactor had its operation regime modified for 64 hours without interruption, aiming at the production of Sm-153 and service to the scientific body of IPEN-CNEN / SP.

The IEA-R1 nuclear reactor has been used intensively for more than 50 years, being one of the oldest and best-used research reactors in the world, according to the International Atomic Energy Agency (IAEA), for research and development activities [1]. It should be noted here that, in addition to research, the reactor is, also, thoroughly used for the generation of several types of products and services, among which the production of primary radioisotopes is the most important, for the preparation of radiopharmaceuticals used in Nuclear Medicine [1]. During the last 15 years, the reactor underwent several alterations in its vital systems and equipment, due to wear and tear, and these improvements continue, in view of the proposed increase of the reactor power from the current 4.5 to 5.0 MW and operation of 120 hours per week, in the future.

\footnotetext{
*acirodri@ipen.br
}

These changes will meet the growing demand for radioisotope production for use in medicine, such as Sm-153, I-131, and Mo-99. Aiming at this new rhythm of work and the adequacy of the installation for higher power, a project for the continuous upgrading of the reactor was started.

\subsection{Objective}

The objective of this work was the study and design of a wet storage system to double the current storage capacity of spent fuel elements of the IEA-R1 research reactor, using the borated material in the racks manufacture.

\subsection{Storage of Fuel Elements in the IEA-R1 Research Reactor}

The irradiated fuel elements are stored in stainless steel racks located in the storage compartment of the reactor pool, as shown in Figure 1 . In the storage compartment of the reactor pool, there are three hanging racks affixed to the pool wall, with a capacity of storing $24+24+36$ fuel elements, reaching a total of 84 positions, where the spent fuel elements are stored. At each position of the fuel storage racks, aluminum coating boxes are installed to minimize galvanic corrosion between the fuel element plates and the structural material of the storage basing. 
A.C.I. Rodrigues et al., High density storage racks for spent fuel..., RAD Conf. Proc., vol. 3, 2018, 123-126

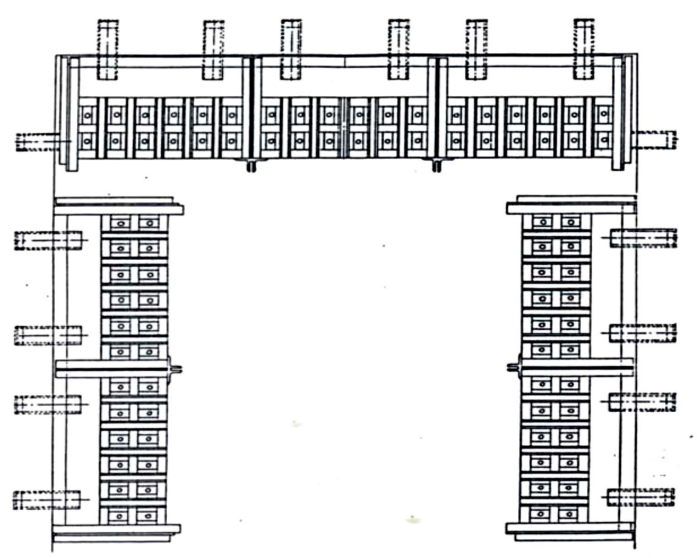

Figure 1. Top view of the storage racks in the reactor pool.

\subsection{Current Situation of the Storage Racks}

Currently, the racks available for storage of the irradiated fuel elements present an occupation fraction greater than $83 \%$ (70 occupied positions out of the total 84), as shown in Table 1 , with the current level of use of the racks.

Thus, maintaining the present operating conditions of the reactor (32 hours per week, at 4.5 MW of power), we will have a utilization rate of $\sim 3$ positions/year, which results in an autonomy of around 5 years of operation, since we do not have a definite destination for this type of waste.

Considering that the estimate IEA-R1 reactor lifetime is about another 20 years, it will be necessary to increase the storage capacity of the spent fuel [2]. To make it possible, the neutron-absorbing material has to be used in its construction, in view of the limited availability of space within the reactor pool, also, to meet the safety requirements of the licensing agency (CNEN) and Standards established by the IAEA.

Table 1. Comparison of the current racks with the new units proposed in the project (condition in March 2016) (source: owned)

\begin{tabular}{l|llll}
\cline { 2 - 5 } & Total positions & $\begin{array}{l}\text { Occupied } \\
\text { positions } \\
(\text { March/2016) }\end{array}$ & $\begin{array}{l}\text { Empty } \\
\text { positions }\end{array}$ & $\begin{array}{l}\text { Expected } \\
\text { autonomy } \\
\text { (years) }\end{array}$ \\
\hline Present racks & 84 & 70 & 14 & $\frac{\mathbf{1 4}}{\mathbf{3}} \cong 4.6$ \\
Proposed racks & 168 & 70 & 98 & $\frac{98}{\mathbf{3}} \cong 32.6$ \\
\hline
\end{tabular}

\section{MATERIALS AND METHODS}

After studies that led to the accomplishment of this work, the traditional option of the borated- stainless steel basin was discarded due to the need of an internal aluminum coating and constant inspection of its integrity, ensuring that there is no contact between the aluminum structure of the fuel element and the stainless steel from the basing, generating galvanic corrosion [3]. Such an inspection procedure is quite laborious and expensive since it has to be carried out underwater [4].
From the analysis of the literature on high-density racks for the storage of irradiated fuel elements from research reactors, BORALCAN ${ }^{\mathrm{TM}}$ was chosen for this work [5].

BORALCAN ${ }^{\mathrm{TM}}$ is a metal matrix composite (MMC) made by Rio Tinto Alcan, comprising an aluminum alloy (1100 or 6351) added with nuclear grade $\mathrm{B}_{4} \mathrm{C}$ powder and titanium (Ti). The addition of small amounts of $\mathrm{Ti}(<2.5 \%)$ in the molten aluminum makes the mixture of $\mathrm{B}_{4} \mathrm{C}$ particles more stable and uniform, avoiding interactions of $\mathrm{Al}$ with $\mathrm{B}_{4} \mathrm{C}[6]$.

\subsection{The MCNP-5 Code}

Monte Carlo N-Particle is a general-purpose transport code that considers the continuous spectrum of energy, generalized geometries, time dependence and neutron/ photon/electron set effect. The neutron energy range is up $20 \mathrm{MeV}$ for all nuclides and up to $150 \mathrm{MeV}$ for some nuclides, with the used ENDF/B-VI and ENDF/B-VII nuclear data libraries. It can calculate keff values for fission systems, as well as keff for critical systems. The code treats an arbitrary threedimensional configuration of materials in geometric cells delimited by first or second degree and fourthdegree elliptical toroid surfaces [7].

For the development of the project, the computational code MCNP version 5 was used because it is a widely accepted calculation tool and highly indicated in the analysis of this type of problem [7].

\subsection{The MCNP Model}

The computationally simulated arrangement with the MCNP- 5 consisted of a $16 \mathrm{X}_{3}$ basin totaling 48 fuel elements, what would double the capacity of the current racks of 24 elements, yet occupying the same physical space, that is, with practically the same external dimensions. Figure 2 shows a 3D illustration comparing the current basin with that to be constructed.

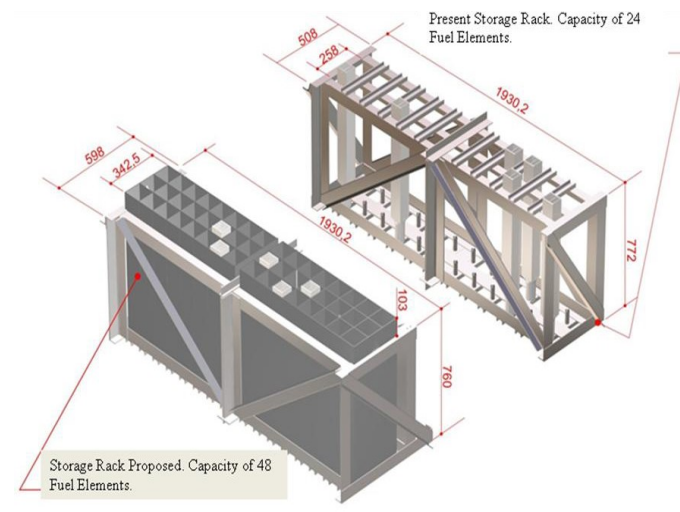

Figure 2. 3D comparative drawing of the two racks with dimensions.

\subsection{Results Obtained in the Calculation of keff}

For keff calculation, four cases were analyzed: two with the ENDF / B-VI library (cases 1 and 2) and two with the ENDF / B-VII library (cases 3 and 4). In the 
A.C.I. Rodrigues et al., High density storage racks for spent fuel..., RAD Conf. Proc., vol. 3, 2018, 123-126

analysis of the cases, two situations were considered: one with the BORALCAN ${ }^{\mathrm{TM}}$ absorber and the other with pure aluminum. For the simulation, it was considered that the rack was fully loaded with new fuel elements (o\% of burning) of $\mathrm{U}_{3} \mathrm{Si2}-\mathrm{Al}$ of $19.95 \%$ enrichment in U-235, type MTR (Material Testing Reactors), corresponding to the most critical condition in terms of criticality risk (called a more conservative condition).

In our simulations the following data were used for KCODE:

\section{kcode 100000130500}

Where the number 100000 corresponds to the number of neutrons or simulated histories, 1 means the initial keff value estimated, 30 are the initial cycles that will be discarded and 500 the number of cycles that will be calculated in total, remaining 470 active.

After the line with the KCODE command, the position (coordinates $\mathrm{x}, \mathrm{y}$ and $\mathrm{z}$ ) where the source is located is defined, which is defined with the KSRC command. This point must be located inside a cell that contains fissile material, which in our case is the U235.

The structure of the output of the program results is divided into phases of the simulation, where the first half corresponds to the results obtained in the initial 235 iterations (active cycles) and the second half, in the next 235 final iterations. The final result is calculated taking into account all the active cycles, in our case, 470. Table 2 presents an outline of the results for keff.

Table 2. Summary of the results obtained for keff

\begin{tabular}{|c|c|c|c|}
\hline SIMULATION & keff & $\begin{array}{l}\text { STANDARD } \\
\text { DEVATION }\end{array}$ & USED LIBRARY \\
\hline CASE 1 (BORALCAN ${ }^{\mathrm{TM}}$ ) & 0.52872 & \pm 0.00011 & ENDF/B-VI (1993-1994) \\
\hline CASE 3 (BORALCAN ${ }^{\mathrm{TM}}$ ) & 0.52846 & \pm 0.00011 & ENDF/B-VII (2007/2008) \\
\hline CASE 2 (without absorber) & 0.99762 & \pm 0.00011 & ENDF/B-VI (1993-1994) \\
\hline CASE 4 (without ab sorber) & 1.00335 & \pm 0.00011 & ENDF/B-VII (2007/2008) \\
\hline
\end{tabular}

\section{CONCLUSION}

Based on the results obtained, it can be safely concluded that by doubling the amount of fuel elements burned in the basin, the limit established in the IAEA and CNEN standards for criticality (keff $<0.95$ ) will be met, as long as the absorber material is used.

From Table 2, we conclude that for the new racks it is necessary to use the neutron absorber (in our case BORALCAN $^{\mathrm{TM}}$ ), since the system without the absorber can reach the criticality and, possibly, the supercriticality (keff>1), as it may be verified in Cases 2 and 4, respectively.

In Cases 1 and 3 (with BORALCAN ${ }^{T M}$ ) the difference is only the nuclear data library used in the simulation, where we can look the results were very similar.

The preparation of the new racks, proposed in this work, should be done using the absorber material with
$25 \%$ (of volume) aluminum boron carbide alloy 1100 that is produced by Rio Tinto Alcan.

Thus, we will meet all the requirements of the standards and will be able to double the storage capacity of spent fuel elements of the current racks, increasing the operational autonomy of the IEA-R1

\section{Acknowledgements:}

To the Institute of Energy and Nuclear Research (IPEN-CNEN / SP), which allowed the development of this work.

To the International Atomic Energy Agency (IAEA) that sponsored my participation in technical meetings that contributed much to this work.

To Professor Dr. Tufic Madi Filho for the guidance, suggestions, patience, and support in the development of this work.

To the Professor Dr. Paulo de Tarso Dalledone Siqueira for the enormous assistance during the elaboration of the modeling, simulations and the provision of the code MCNP-5.

To Msc. Walter Ricci Filho, head of the IEA-R1 Reactor, for the suggestion and encouragement of this work and Davilson Gomes da Silva for his excellent work in graphic arts.

\section{REFERENCES}

1. R. N. Saxena, "The IEA-R1 research reactor 50 years of operating experience and utilization" in Proc. IAEA International Conference on Safe Management and Utilization of Research Reactors, Sydney, Australia, 2007.

Retrieved from: https://www-

pub.iaea.org/mtcd/meetings/PDFplus/2007/cn156/cn1 56presentations/cn156 Saxena.pdf; Retrieved on: Feb. 24, 2018

2. A. C. I. Rodrigues, T. Madi Filho, W. And Ricci Filho, "Borated stainless steel storage project to the spent fuel of the IEA-R1 reactor," in Proc. International Nuclear Atlantic Conference (INAC 2013), Recife, Brazil, 2013. Retrieved from: https://inis.iaea.org/collection/NCLCo llectionStore/ Public/45/071/45071042.pdf? $r=1 \& r=1$; Retrieved on: Feb. 24, 2018

3. A. C. I. Rodrigues, T. Madi Filho, P. T. D. Siqueira, W. Ricci Filho, "Design of a new wet storage rack for spent fuels from IEA-R1 reactor," in Proc. International Nuclear Atlantic Conference (INAC 2015), São Paulo, Brazil, 2015.

Retrieved from: https://inis.iaea.org/collection/NCLCo llectionStore/_Public/47/017/47017700.pdf?r=1\&r=1; Retrieved on: Feb. 24, 2018

4. Criticality Safety in the Handling of Fissile Material, IAEA Safety Standards Series No. SSG-27, IAEA, Vienna, Austria, 2014.

Retrieved from: https://wwwpub.iaea.org/MTCD/Publications/PDF/Pub1594 web51742615.pdf; Retrieved on: Feb. 24, 2018

5. A. C. I. Rodrigues, "Study and design of the new baskets with boron for storage elements fuel burned of the IEAR1 reactor," M.Sc. dissertation, Nuclear and Energy Research Institute, São Paulo, Brazil, 2016. DOI: 10.11606/D.85.2016.tde-16092016-115614

6. Material Qualification of Alcan Composite for Spent Fuel Storage, NET-259-03, Northeast Technology Corp., Kingston (NY), USA, 2008. 
A.C.I. Rodrigues et al., High density storage racks for spent fuel..., RAD Conf. Proc., vol. 3, 2018, 123-126

Retrieved from: https://www.nrc.gov/docs/ML1319/M L13199A039.pdf;

Retrieved on: Feb. 24, 2008

7. MNCP - A General Monte Carlo N-Particle Transport

Code, Version 5, Los Alamos National Laboratory, Los Alamos (NM), USA, 2008
Retrieved from: https://mcnp.lanl.gov/pdf files/la-ur03-1987.pdf;

Retrieved on: Feb. 14, 2018 